ANUARIO DE ESTUdios MEDIEVALES

50/1, enero-junio de 2020, pp. 505-532

ISSN 0066-5061

https://doi.org/10.3989/aem.2020.50.1.18

\title{
DE LA INFANCIA A LA JUVENTUD: \\ EL ENTORNO SOCIAL DE LA INFANTA JUANA DE ARAGÓN A TRAVÉS DE SU LIBRO DE CUENTAS (1469-1472)*
}

\author{
FROM CHILDHOOD TO YOUTH: \\ THE SOCIAL ENVIRONMENT OF THE INFANTA JUANA OF ARAGON \\ THROUGH HER BOOK OF ACCOUNT (1469-1472)
}

IRENE VELASCO MARTA

Universidad de Zaragoza

https://orcid.org/0000-0001-6864-0344

\begin{abstract}
Resumen: El presente artículo estudia el entorno social de la infanta Juana de Aragón a través del libro de cuentas elaborado por su tesorero, Luis de Santángel, entre 1469 y 1472. Mediante la consulta de esta fuente particular y de documentación auxiliar, se pretende poner de relieve la relevancia histórica de esta figura, que ha pasado desapercibida por la historiografía reciente, y analizar la estructura y composición de la Casa de la Infanta en el momento de su creación, así como la naturaleza de las relaciones trazadas en su interior. También se aborda la dimensión de la Casa de la Infanta como espacio femenino de carácter oficial, y se analizan las posibilidades de autonomía y acción política que esta institución confería a su titular, así como las oportunidades de empleabilidad y promoción social ofrecidas a las mujeres que se integraban en su seno.
\end{abstract}

Palabras clave: Juana de Aragón; Casa de la Infanta; corte; libro de cuentas; entorno social; Corona de Aragón.

Abstract: This article studies the social environment of the Infanta Juana of Aragon through the book of accounts written by her treasurer, Luis de Santangel, between 1469 and 1472. By consulting this source and auxiliary documentation, the aim is to highlight the historical significance of this figure, which has gone unnoticed by recent historiography, and to analyse the structure and composition of the Infanta's Household as well as the nature of the relationships traced inside it. It also considers the scope of the Infanta's Household as an official feminine space and analyses the possibilities of autonomy and political action that this institution conferred on its head and the opportunities for employment and social promotion that it offered the women who formed part of the Infanta's Household.

Keywords: Juana of Aragon; Infanta's household; court; book of account; social environment; Crown of Aragon.

\section{SUMARIO}

1. Introducción.- 2. Breve trayectoria vital de Juana de Aragón (1455-1517)-- 3. Estructura y composición de la Casa de Juana de Aragón.- 4. El entorno femenino de la infanta Juana de Aragón.- 5. Conclusiones.- 6. Bibliografía citada

\footnotetext{
* Este trabajo forma parte de la actividad científica desarrollada por el Grupo de Investigación de Referencia CEMA, reconocido por el Gobierno de Aragón, ref. H20-17R (2017-2019); y se ha realizado en el marco de un contrato de personal investigador predoctoral en formación para el período 2018-2022, financiado por el Gobierno de Aragón y el Programa Operativo FSE Aragón 2014-2020.

Citation / Cómo citar este artículo: Velasco Marta, Irene (2020), De la infancia a la juventud: el entorno social de la infanta Juana de Aragón a través de su libro de cuentas (1469-1472), "Anuario de Estudios Medievales" 50/1, pp. 505532. https://doi.org/10.3989/aem.2020.50.1.18

Copyright: (C) 2020 CSIC. Este es un artículo de acceso abierto distribuido bajo los términos de la licencia de uso y distribución Creative Commons Reconocimiento 4.0 Internacional (CC BY 4.0).
} 


\section{INTRODUCCIÓN ${ }^{1}$}

Las investigaciones que, dentro del campo de la queenship ${ }^{2}$ o reginalidad $^{3}$ bajomedieval, ponen el foco en las casas de reinas e infantas, han experimentado un considerable desarrollo estos últimos años. Integrada por una serie de oficiales, servidores y otras personas bajo su control y protección, esta institución de difusos contornos pero de excepcionales contenidos, en la que lo relativo al gobierno y administración del reino se muestra en próxima relación con lo doméstico ${ }^{4}$, no sólo estaba concebida para satisfacer las necesidades básicas de su titular sino, también, para asegurar su prestigio y representatividad, facilitar la gestión más o menos autónoma de sus rentas y patrimonio y articular en torno a ella una serie de apoyos sociales, políticos y económicos que constituían el principal pilar de su influencia en las distintas esferas de toma de decisiones que atañían al funcionamiento y buen desarrollo del gobierno. En otras palabras, la Casa de la Reina o, en su caso, de la Infanta

podría definirse como la estructura organizativa compuesta por aquellos oficiales de tipo burocrático, financiero y doméstico que se encontraban al servicio de la reina, y que hacían posible la demostración, expresión y representación de la reginalidad ante la corte y el reino, en lo administrativo, político y simbólico 5 .

La Casa constituía el epicentro de una enorme red que, por medio de sus integrantes, ligaba estrechamente a esta institución con otros grupos y espacios de poder. Mediante la inclusión de determinados oficiales a su servicio, la reina, princesa o infanta en cuestión disfrutaba de contactos con individuos procedentes de las oligarquías municipales y los principales linajes nobiliarios, lo que favorecía la extensión de su influencia a otras instituciones de la Corte a través de estos mismos oficiales. La Casa de la Infanta, como la de la Reina, actuaba como un gran contenedor de relaciones ${ }^{6}$ de amistad, alianza y solidaridad que aseguraban un flujo constante y bidireccional de beneficios

${ }^{1}$ Abreviaturas utilizadas: ACA = Archivo de la Corona de Aragón; AHPNZ = Archivo Histórico de Protocolos Notariales de Zaragoza; AMZ = Archivo Municipal de Zaragoza; $\mathrm{C}=$ Cancillería; $\mathrm{MR}=$ Maestre Racional; reg. = registro; $\mathrm{RP}=$ Real Patrimonio.

${ }^{2}$ Término definido como "a repertoire of collective norms, institutional structures, and strategies for participation within the public political sphere of monarchy that included, but was not limited to, governance" en Earenfight 2005, p. XVI. A propósito de la Queenship véase también Pelaz 2013.

${ }^{3}$ Sobre el concepto de reginalidad véase Silleras 2003; Pelaz, Val 2015; García 2017.

${ }^{4}$ Muñoz 2002, p. 71.

${ }^{5}$ Pelaz 2017, p. 32.

${ }^{6}$ Ibidem, p. 18. 
entre la titular y quienes se emplazaban a su servicio. De este modo, la primera lograba acrecentar su prestigio, recursos económicos y capacidad de acción política mediante la presencia de determinadas personas en su entorno más próximo mientras que, en contrapartida, quienes servían y rodeaban a reinas, princesas o infantas no sólo veían incrementado su prestigio sino que obtenían importantes retribuciones económicas y la posibilidad de disfrutar de una mayor cercanía a diversas esferas de poder en el marco de la Corte, así como a la propia figura reginal. Además, su inclusión en la Casa abría una puerta directa de ascenso social a través de la cual podían llegar a ocupar cargos de una considerable entidad dentro de este espacio, o promocionar a otras instituciones cortesanas en virtud de su fidelidad y servicios prestados.

Por todo ello, el presente ensayo busca aproximarse al conocimiento de esta institución mediante el análisis particular de la Casa de la infanta Juana de Aragón (1455-1517), hija de Juana Enríquez y Juan II de Aragón, a partir de la información contenida en el libro de la tesorería de la infanta que su tesorero, Luis de Santángel, elaboró entre 1469 y 1472 y que se conserva en la sección Real Patrimonio del $\mathrm{ACA}^{7}$. Este libro de cuentas, redactado en catalán por obra de una única mano, detalla algunos de los ingresos y buena parte de los gastos realizados en la Casa de la infanta Juana durante las mencionadas fechas, que abarcan el momento de su creación y los tres años inmediatamente posteriores. La fuente manejada se encuentra incompleta, existiendo entre sus 113 folios considerables lagunas en años como 1471, para el cual sólo se recogen cuatro referencias relacionadas con pagos relativos a un viaje realizado por la infanta ${ }^{8}$. Asimismo, aunque la descripción de los gastos del resto de años es más minuciosa, no sucede lo mismo con los ingresos: únicamente se contemplan cuatro entradas correspondientes al año 1469 y una a 1470 , en las cuales se especifican las cantidades destinadas por el rey para el mantenimiento de la Casa de su hija y la identidad del individuo que realizó cada entrega, pero se omiten datos, como la procedencia de las rentas destinadas a esta institución, que podrían resultar de gran interés.

Por otra parte, los saltos de fechas y vueltas atrás en el tiempo dentro de las referencias relativas a cada año parecen indicar que este cuaderno constituye la copia o puesta por escrito de anteriores anotaciones realizadas por el tesorero. Pese a ello, el libro de la tesorería de Juana de Aragón nos ofrece abundante información sobre el número de oficiales que servían en su

\footnotetext{
${ }^{7}$ Junto con el libro de tesorería de la infanta se han empleado otras fuentes con objeto de identificar de forma más precisa a quienes componían el entorno de Juana de Aragón: fundamentalmente documentación notarial del AHPNZ y registros de la cancillería de Juan II conservados en el ACA.

${ }^{8}$ ACA, RP, MR, 619, ff. 65r-67r.
} 
Casa, los cargos que desempeñaban y los salarios y complementos económicos que recibían, pudiendo así reconstruir de la forma más precisa posible el entorno social de su titular en los primeros años de su juventud. Además, el índice onomástico incluido en las últimas páginas del libro de cuentas facilita la identificación de aquellos individuos que rodearon a la infanta durante un periodo de tiempo muy preciso, y los datos relativos a gastos realizados fuera de la Casa -como los derivados de viajes, compra de determinados productos o visitas médicas- favorecen el trazado de redes relacionales que sobrepasan el ámbito de la Corte.

\section{BREVE TRAYECTORIA VITAL DE JUANA DE ARAGÓN (1455-1517)}

Resulta más que llamativa la escasa atención historiográfica recibida por Juana de Aragón, así como lo temprano de la misma, a pesar de su destacada acción política como lugarteniente general de Cataluña, reina consorte de Nápoles y lugarteniente general de Nápoles. En este sentido, ya a finales del siglo XIX Benedetto Croce analizó, con un enfoque más literario que histórico, la composición de la Corte napolitana de Juana de Aragón y su hija, conocidas por el epíteto de las tristes reinas ${ }^{9}$. También Adele Scandone abordó ambas figuras de manera conjunta en el que probablemente sea el estudio más extenso dedicado a estas reinas ${ }^{10}$. Tras ella, Félix Fernández Murga, Mario Gaglione y Vicente Genovés realizaron diversas aproximaciones al personaje de Juana de Aragón ${ }^{11}$, aunque las lagunas existentes en torno a esta figura histórica continúan siendo evidentes y se intensifican en los veinte años previos a la introducción de la infanta en la esfera política napolitana.

Juana de Aragón nació en Barcelona en 1455 fruto del matrimonio entre Juan II de Aragón y Juana Enríquez. De su infancia apenas existen referencias previas a 1463 , cuando su madre y ella pasaron diez meses encerradas en una fortaleza como rehenes del arzobispo de Toledo como consecuencia de los constantes enfrentamientos bélicos entre Aragón y Castilla. Más allá de este episodio, es muy probable que Juana pasase buena parte de su infancia junto a su madre, disponiendo de un cierto número de oficiales propios dedicados a su cuidado dentro de la Casa de la Reina, como Leonor de Heredia, su nodriza $^{12}$, y Juan de Ureña -antiguo camarero de Juan II- y su esposa, Isabel Rodríguez Muñoz, quienes en 1461 fueron nombrados por el rey camareros

${ }^{9}$ Croce 1894.

${ }^{10}$ Scandone 1929.

${ }^{11}$ Genovés 1943; Fernández 1959. Más específico resulta Gaglione, sin año.

${ }^{12}$ ACA, C, reg. 3417, f. 127v. 
de la infanta de forma vitalicia ${ }^{13}$. No obstante, no sería hasta la muerte de su madre, en 1468, cuando la infanta pasase a contar con un espacio propio y un número considerable de servidores privativos de su persona, muchos de los cuales, como Luis de Santángel (tesorero), Bernat Margarit (camarlengo) y Juan de Medina (capellán), habían sido designados como tales por Juana Enríquez en su testamento ${ }^{14}$. Igualmente, en aquel momento confluyeron en el entorno más cercano a la infanta mujeres procedentes de los principales linajes nobiliarios de Aragón, Cataluña y Valencia como Brianda de Mur, Damieta de Alagón y Orfresina de Vilaragut ${ }^{15}$. Muchos de los individuos integrados en esta primera Casa de la Infanta procedían de las de Juan II y Juana Enríquez, si bien resulta difícil cuantificar hasta qué punto la composición inicial obedecía a la voluntad de las figuras materna y paterna o si, por el contrario, Juana de Aragón tuvo alguna capacidad de decisión en ese momento de tránsito entre la infancia y la adolescencia ${ }^{16}$. Lo que sí resulta claro es que el hecho de contar con una institución propia, oficiales a su servicio y la renta anual de 4.000 florines que Juana Enríquez le legó en su testamento confirieron a la infanta, que en aquel momento contaba con unos trece años de edad, una considerable autonomía y capacidad de acción que facilitaron el trazado de ciertas redes de apoyo, afectividad, solidaridad e influencia que resultarían de vital importancia tras su entrada de lleno en la esfera política aragonesa en 1475, a raíz de su nombramiento como lugarteniente general de Cataluña.

De los años que median entre la muerte de la reina y el nombramiento de la infanta como lugarteniente apenas se conserva información, si bien sabemos que Juana de Aragón se asentó junto con su Corte en la ciudad de Zaragoza. De este modo, no sería de extrañar que desempeñase ciertas tareas de gobierno en el reino de Aragón ${ }^{17}$ mientras Juan II y Fernando II hacían frente a los enfrentamientos surgidos en distintos puntos de la Corona. En este sentido, no debemos olvidar que los años que recoge este libro de cuentas corresponden a la última fase de la Guerra Civil Catalana (14621472), que enfrentó a la nobleza rural, que buscaba mantener sus prerroga-

${ }^{13}$ ACA, C, reg. 3359, ff. 114v-115r.

${ }^{14}$ Fernández 1959, p. 176.

${ }^{15}$ Genovés 1943, pp. 7-8.

${ }^{16}$ Para documentar este aspecto hubiera sido interesante contar con los nombramientos de los oficiales de la Casa de la Infanta entre 1469 y 1472, pero en la cancillería de Juan II son muy escasas las referencias relativas a los servidores de su hija.

${ }^{17}$ Entre otras cosas, sabemos que el 23 de julio de 1472 Juana de Aragón solicitó a los jurados de Zaragoza la organización de una recepción para los embajadores del duque de Borgoña, que pretendían pasar unos días en la ciudad antes de proseguir su camino hacia Castilla para encontrarse con el rey: AMZ, Libros de Actas, 6, f. 116v. Regesta en Falcón 2006, p. 268. 
tivas sobre los payeses de remensa, con los intereses realistas ${ }^{18}$. Tras ella, Juan II decidió concentrar todos sus esfuerzos en el frente abierto en Italia contra Luis XI de Francia, por lo que nombró a su hija como lugarteniente general de Cataluña. Además de un puesto de tal relevancia, que ocupó entre octubre de 1475 y abril de 1477, en 1475 la infanta recibió de su padre el condado de Ampurias y ciertos territorios en el reino de Valencia ${ }^{19}$ que le permitieron incrementar su capacidad económica y poder fáctico en la Corona de Aragón.

Poco después, el 5 de octubre de 1476, se firmaron en Tudela las capitulaciones matrimoniales de Juana de Aragón y Ferrante I, viudo de Isabel de Claramunt desde 1465. La ceremonia nupcial tuvo lugar el 14 de septiembre de 1477, y el 18 de ese mismo mes la infanta fue coronada como Juana III de Nápoles. Durante su estancia en su nuevo reino, Juana de Aragón desarrolló una importante actividad de mecenazgo cultural de la cual dan noticia abundantes producciones literarias de la época ${ }^{20}$, y se rodeó de un extenso séquito integrado por damas y doncellas de los principales linajes napolitanos, como Juana Castriota, María Cantelmo, Diana Gambacorta, la duquesa de Gravina y la marquesa de Toralto. Pero junto a la nueva reina se ubicó también un nada desdeñable número de nobles castellanas, aragonesas, valencianas y catalanas como María Enríquez, Ángela de Vilaragut, Juana Carroz y Violante Centelles $^{21}$, que le habrían acompañado en su viaje y constituido su principal punto de apoyo en sus primeros meses como reina de Nápoles mientras ella se familiarizaba con la lengua, usos y costumbres napolitanos y se esforzaba por asentar su poder estableciendo contactos con individuos de los principales linajes y oligarquías del reino ${ }^{22}$, muchos de los cuales acabarían entroncando con mujeres de su entorno ${ }^{23}$.

\footnotetext{
${ }^{18}$ Para más información, véase Vicens 2003.

${ }^{19}$ ACA, C, reg. 3389, ff. 25r-26r.

${ }^{20}$ Véase Vázquez, Dechado de amor hecho por Vazquez a peticion del Cardenal de Valencia, endereçado a la Reyna de Napoles ed. Françoise Vigier, pp. 372-390.

${ }^{21}$ Croce 1894, pp. 362-363.

${ }^{22}$ La composición de la Casa de la Reina resulta determinante, en el caso de las soberanas extranjeras, para asentar su posición en la Corte y adquirir los conocimientos suficientes para participar de las dinámicas políticas y manejarse con soltura en los espacios de poder y toma de decisiones de su nuevo reino. Este proceso de aprendizaje de las reinas foráneas, estudiado en García 2013 para el caso de María de Castilla y en Earenfight 2018 para el de Catalina de Aragón, se garantizaba mediante la integración en el entorno más cercano a la soberana de mujeres provenientes de su lugar de origen, algunas de ellas con una larga trayectoria a su servicio junto con otras propias del reino de llegada, un aspecto que también puede documentarse en el caso de Juana de Aragón.

${ }^{23}$ En el Dechado de amor hecho por Vazquez a peticion del Cardenal de Valencia, endereçado a la Reyna de Napoles se menciona, entre otros, el matrimonio de Violante Centelles y Angelo Galeotto. Vázquez, Dechado de amor, ed. Vigier, p. 381.
} 
En 1481 Juana de Aragón fue nombrada lugarteniente general del reino de Nápoles por Ferrante I mientras éste se ocupaba de la defensa de las costas tras el desembarco de los turcos en Otranto. La reina ejerció dicho cargo hasta la muerte de su marido el 25 de enero de 1494, momento en que adoptó el epíteto de la triste reina ${ }^{24}$, pero volvió a ocupar la lugartenencia durante los reinados de Alfonso II (1494-1495) y Ferrante II (1495-1496), contribuyendo bajo este segundo reinado a la reconquista del Castel dell 'Ovo, que había sido tomado por los franceses. Tras la muerte de Ferrante II, Juana III quiso hacer valer los derechos de su linaje al trono napolitano promoviendo la coronación de su hija, Juana IV, o la de Fernando el Católico, pero los barones de Nápoles aclamaron como rey a Federico III, hermano de Alfonso $\mathrm{II}^{25}$. A pesar de sus malas relaciones con la antigua soberana, Federico III ratificó a Juana III como lugarteniente general del reino, un nombramiento que no debe ser entendido como un privilegio o una suerte de reconocimiento a su madrastra sino, más bien, como una forma de mantener bajo control la considerable influencia que Juana III ejercía sobre las instituciones napolitanas.

Finalmente, Juana III terminó renunciando al cargo de lugarteniente general en 1499 para regresar a la Península Ibérica, donde permaneció en la Corte de los Reyes Católicos hasta 1506. Ese año, con el objeto de hacer efectivo el Tratado de Lyon firmado en 1504 por Fernando II y Luis XII de Francia, por el cual el soberano francés renunciaba a los territorios napolitanos de los que se había visto beneficiado tras la división del reino en el Tratado de Granada (1500), regresó a Nápoles junto a su hermano, quien la nombró lugarteniente general hasta la llegada del nuevo virrey, Ramón de Cardona, algunos meses después. Ésta supuso la breve y última lugartenencia de Juana III, tras la que permaneció en Nápoles junto a su hija hasta el momento de su muerte, el 7 de enero de 1517, cuando contaba con 62 años $^{26}$.

\section{ESTRUCTURA Y COMPOSICIÓN DE LA CASA DE JUANA DE ARAGÓN}

El tratamiento en una base de datos prosopográfica de la información obtenida tras la consulta del libro de cuentas de la infanta nos ha permitido

\footnotetext{
${ }^{24}$ El uso de la expresión "triste reina" no fue exclusivo de Juana de Aragón, sino que su manejo como fórmula convencional para referirse a las reinas viudas en Castilla ha sido documentado en Echevarría 2002 para el caso de Catalina de Lancaster y en Pelaz 2018 para el de Leonor de Alburquerque.

${ }^{25}$ Los lazos familiares existentes entre todos estos personajes se observan en el árbol genealógico de Juana de Aragón incluido al final de este artículo.

${ }^{26}$ Hemos aludido muy sucintamente a la etapa napolitana de Juana de Aragón. Para más información véase Scandone 1929; Fernández 1959; Gaglione, sin año.
} 
identificar a un total de 84 individuos que formaron parte, temporal o permanentemente, del entorno social de Juana de Aragón entre 1469 y 1472. De ellos, 65 registros hacen referencia a oficiales y otras personas al servicio de la infanta, mientras que 19 aluden a artesanos, mercaderes y prestamistas que desarrollaron su actividad laboral en la ciudad de Zaragoza y mantuvieron, en consecuencia, una relación comercial con Juana de Aragón durante el tiempo que ésta pasó en la capital aragonesa. Asimismo, esta información nos sitúa ante la estructura de una Casa que bebe directamente de la propuesta por las Ordinacions que Pedro IV dictó en $1344^{27}$. En ella, la autoridad y responsabilidad del buen gobierno de la institución recaían sobre cuatro oficiales, el mayordomo, el camarlengo, el canciller y el maestre racional, bajo cuyo mando se emplazaban un buen número de servidores. En este caso, 37 varones y 3 mujeres que recibieron por su labor un salario o quitación ordinaria oscilante, en función del cargo desempeñado, entre los 135 y los 900 sueldos barceloneses, a los que se solían añadir ciertos complementos y ayudas de costa. Además, confluían en la Casa otras personas que, como las 16 damas y doncellas de la infanta, no desempeñaron ningún cargo oficial pero recibieron por su integración en el séquito de Juana de Aragón quitaciones ordinarias oscilantes entre los 90 y los 120 sueldos barceloneses, así como ayudas de costa y otro tipo de complementos destinados específicamente a la adquisición de vestidos. Finalmente, habitaron en la Casa de Juana de Aragón una enana ${ }^{28}$ y ocho esclavos -de los cuales sólo hemos podido identificar a dos, $\mathrm{Ana}^{29}$ y Martín el $\mathrm{Negro}^{30}$ - que no dispusieron de ningún tipo de remuneración más allá de su alimentación y vestido.

\footnotetext{
${ }^{27}$ Pedro IV de Aragón, Ordinacions de la Casa i Cort de Pere el Cerimoniós, ed. Francisco M. Gimeno, Daniel Gonzalbo y Josep Trenchs, 2009. A propósito de las Ordinaciones de Pedro IV, resulta interesante la consulta de Beauchamp 2013, pp. 43-56.

${ }^{28}$ ACA, RP, MR, 619, f. 50v.

${ }^{29}$ Ibidem, f. 56r.

${ }^{30}$ Ibidem, f. 50v.
} 


\begin{tabular}{|c|c|c|}
\hline \multirow{10}{*}{ PALACIO } & \multicolumn{2}{|l|}{ Mayordomo } \\
\hline & \multirow{4}{*}{$\begin{array}{l}\text { Cocina, } \\
\text { despensa y } \\
\text { mesa }\end{array}$} & Cocinero \\
\hline & & \begin{tabular}{|l|} 
Ayudante de \\
cocina
\end{tabular} \\
\hline & & Pastelera \\
\hline & & Compradores \\
\hline & \multirow{5}{*}{$\begin{array}{l}\text { Caballerizas } \\
\text { y acemilería }\end{array}$} & $\begin{array}{l}\text { Caballerizo } \\
\text { mayor }\end{array}$ \\
\hline & & Sotacaballerizo \\
\hline & & $\begin{array}{l}\text { Mozos de } \\
\text { espuelas }\end{array}$ \\
\hline & & Sobreacemilero \\
\hline & & Acemileros \\
\hline
\end{tabular}

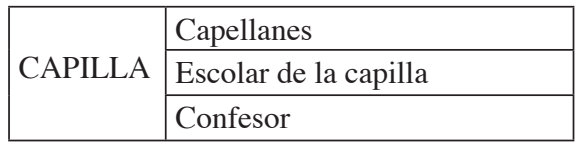

\begin{tabular}{|l|l|}
\hline \multirow{4}{*}{ TESORERÍA } & Tesorero \\
\cline { 2 - 2 } & Escribano del tesorero \\
\cline { 2 - 2 } & \begin{tabular}{l} 
Escriba de ración \\
\cline { 2 - 2 } \\
Lugarteniente del escriba \\
de ración
\end{tabular} \\
\hline
\end{tabular}

\begin{tabular}{|c|c|}
\hline \multirow{18}{*}{ CÁMARA } & Camarlengo \\
\hline & Ayudantes de cámara \\
\hline & Ayudantes del guardarropa \\
\hline & Costurera \\
\hline & Reposteros \\
\hline & Repostero de la plata \\
\hline & Cerero \\
\hline & Ujier de armas \\
\hline & Portero \\
\hline & Paje \\
\hline & Ama \\
\hline & Damas y doncellas \\
\hline & $\begin{array}{l}\text { Contino de las damas y } \\
\text { doncellas }\end{array}$ \\
\hline & $\begin{array}{l}\text { Servidor de las damas y } \\
\text { doncellas }\end{array}$ \\
\hline & $\begin{array}{l}\text { Trinchante de las damas y } \\
\text { doncellas }\end{array}$ \\
\hline & Sirvienta \\
\hline & Enana \\
\hline & Esclavos \\
\hline
\end{tabular}

Fig. 1. Organigrama de la Casa de la infanta Juana de Aragón

Por otro lado, la estructura de la Casa de Juana de Aragón difiere ligeramente de la proporcionada por Pedro IV en sus Ordinaciones, y de forma particular en lo que a los cuatro oficiales principales se refiere. En este sentido, en el presente libro de cuentas no aparece ninguna mención que permita documentar la existencia de una cancillería propia de la infanta Juana, por lo que cabe suponer que esta recurriría a la de su padre para elaborar y expedir documentos o que dichas tareas fuesen ejercidas por su escribano de ración. Tampoco se menciona el cargo de maestre racional, algo que no debe resultar extraño ya que dicho oficial solía ocuparse de desempeñar tareas más generales, entre ellas la de supervisar la tesorería, cuentas y finanzas de los distintos espacios cortesanos. En este sentido, las principales labores administrativas de la Casa de la Infanta fueron realizadas por su tesorero, Luis de Santángel, quien posteriormente tendría que rendir cuentas al maestre racional de la Corte de Juan II. Por su parte, el puesto de mayordomo fue ocupado por Guerau de Espés, encargado de la 
gestión y buen funcionamiento de las caballerizas, la cocina y la despensa, y el de camarlengo por Bernat Margarit, quien dirigió y supervisó la labor del resto de individuos que servían en la cámara de la infanta. Estos tres oficiales -tesorero, mayordomo y camarlengo-, que por las características propias de sus respectivos cargos manejaban unas considerables cotas de autoridad tanto en la Casa de Juana de Aragón como en el ámbito general de la Corte, se beneficiaron con su ubicación en posiciones de considerable proximidad a la infanta, lo que propiciaba el ejercicio de una cierta influencia sobre ella y la participación en la toma de aquellas decisiones de mayor entidad relativas a la Casa.

\begin{tabular}{|c|c|c|c|}
\hline CARGO & OFICIAL & $\begin{array}{l}\text { QUITACIÓN } \\
\text { ORDINARIA }\end{array}$ & $\begin{array}{c}\text { AYUDAS DE } \\
\text { COSTA }\end{array}$ \\
\hline Mayordomo & Guerau de Espés & 620 & 240 \\
\hline Cocinero & Sancho de San Vicente & 180 & - \\
\hline Ayudante de cocina & Luis Francés & 135 & 45 \\
\hline \multirow[b]{2}{*}{ Compradores } & Rodrigo Barón & 360 & 120 \\
\hline & Juan de Morados & 360 & 120 \\
\hline Caballerizo mayor & Jaime Pere Giner & $*$ & $*$ \\
\hline Sotacaballerizo & Juan de Morados & $*$ & $*$ \\
\hline \multirow{6}{*}{ Mozos de espuelas } & Juan de Ferrera & 135 & 45 \\
\hline & Ochoa de Esparza & 135 & 45 \\
\hline & Pedro de Córdoba & 135 & 45 \\
\hline & Pedro de Espinosa & 135 & 45 \\
\hline & Rodrigo de Peralta & 135 & - \\
\hline & Sancho de Posada & 135 & 60 \\
\hline Sobreacemilero & García de Santander & 270 & 180 \\
\hline \multirow[b]{2}{*}{ Acemileros } & Martín de Caparroso & 135 & - \\
\hline & Pedro de la Ferrán & 135 & 45 \\
\hline Camarlengo & Bernat Margarit & 360 & - \\
\hline \multirow[t]{2}{*}{ Ayudantes de cámara } & Gonzalvo de Salorga & 270 & 90 \\
\hline & Diego Cogollos & 270 & 90 \\
\hline Ayudante del guardarropa & Juan de Ureña & 270 & 90 \\
\hline Reposteros & Pedro de Monago & 135 & 45 \\
\hline Cerero & Gómez de León & 180 & 60 \\
\hline Ujier de armas & García de Heredia & 360 & 120 \\
\hline Portero & Álvaro Viejo & 180 & 60 \\
\hline Paje & Alfonso de Fita & 180 & - \\
\hline $\begin{array}{l}\text { Contino de las damas y } \\
\text { doncellas }\end{array}$ & Pedro de León & 180 & - \\
\hline
\end{tabular}




\begin{tabular}{|l|l|c|c|}
\hline CARGO & OFICIAL & $\begin{array}{c}\text { QUITACIÓN } \\
\text { ORDINARIA }\end{array}$ & $\begin{array}{c}\text { AYUDAS DE } \\
\text { COSTA }\end{array}$ \\
\hline $\begin{array}{l}\text { Servidor de las damas y } \\
\text { doncellas }\end{array}$ & Pedro Almazán & - & 60 \\
\hline Sirvienta & Tomasa & 100 & - \\
\hline Tesorero & Luis de Santángel & 900 & 120 \\
\hline Escribano del tesorero & Mateo Ram & 270 & 90 \\
\hline Escriba de ración & Jaime Pere Giner & 720 & 240 \\
\hline $\begin{array}{l}\text { Lugarteniente del escriba de } \\
\text { ración }\end{array}$ & Francesc Estanyol & 270 & 90 \\
\hline \multirow{2}{*}{ Capellanes } & Juan de Medina & 360 & 120 \\
\hline Escolar de la capilla & Juan de Monclús & 360 & - \\
\hline Confesor & Juan de Peralta & 180 & 60 \\
\hline
\end{tabular}

Fig. 2. Quitaciones ordinarias y ayudas de costa de los oficiales de la Casa de la infanta Juana en 1469 (en sueldos barceloneses).

Asimismo, tanto estos oficiales como el confesor de la infanta, Pau Plegat, recibieron las quitaciones ordinarias más elevadas de la Casa: 900 sueldos barceloneses en el caso de Luis de Santángel, 620 en el de Guerau de Espés y 540 en el de Pau Plegat. Junto a ellos, también el escriba de ración de la infanta, Jaime Pere Giner, recibió la considerable cantidad de 720 sueldos, cifra que debe ser matizada teniendo en cuenta que además del cargo de escriba de ración ejerció el de caballerizo mayor, un oficio más protocolario y honorífico que fáctico puesto que la mayor parte de las tareas propias de las caballerizas eran realizadas por los mozos de espuelas ${ }^{31}$. Por su parte, resulta llamativo que Bernat Margarit únicamente cobrase 360 sueldos barceloneses por ejercer de camarlengo, la misma cantidad recibida habitualmente por oficiales como Rodrigo Barón y Juan de Morados, compradores; García de Heredia, ujier de armas; y los capellanes Juan de Monclús y Juan de Medina.

En contraste Isabel de Urrea, de quien sólo se dice ser de casa de la dita senyora infanta ${ }^{32}$, recibió en 1469 una quitación ordinaria de 900 sueldos jaqueses complementada con una ayuda de costa de 300 sueldos, alcanzando una cifra superior a la recibida por Luis de Santángel ese mismo año y considerablemente más elevada que el salario del camarlengo de la infanta. Esto nos lleva a pensar que, aunque no se mencione como tal en su libro de cuentas,

\footnotetext{
${ }^{31}$ Juan de Morados también presenta una situación similar, desempeñando simultáneamente los cargos de comprador y sotacaballerizo.

${ }^{32}$ ACA, RP, MR, 619, f. 41v.
} 
Isabel de Urrea pudo desempeñar el cargo de cambrera o camarera mayor ${ }^{33}$ y que fue, por lo tanto, la responsable de organizar la cámara y a quienes la componían, especialmente a las damas y doncellas que integraban el séquito de Juana de Aragón. Además, el ejercicio de tareas estrechamente ligadas a la intimidad de la infanta y la cercanía propiciada por la convivencia cotidiana de ambas favorecieron el establecimiento de fuertes vínculos de confianza, apoyo mutuo y amistad que se prolongaron durante largo tiempo.

Por otra parte, no podemos pasar por alto la importancia de la Casa de la Infanta como plataforma de ascenso social. Esta institución, firmemente imbricada en el seno de la Corte y estrechamente conectada con otros espacios de poder, ofrecía a quienes servían en ella la posibilidad de acrecentar su prestigio y su capital económico y social, así como participar de un auténtico cursus honorum cuyos cargos y gradación quedaban determinados por la confianza que la infanta depositaba en estas personas y el compromiso y buen hacer que ellas, en contrapartida, demostraban, lo que propiciaba la recepción de salarios o cargos más ventajosos tanto en su Casa como en otras instituciones cortesanas. En este sentido, el libro de cuentas analizado recoge los primeros años de funcionamiento autónomo de la Casa de Juana de Aragón, por lo que buena parte de los oficiales emplazados a su servicio habían sido seleccionados entre los miembros del entorno de Juan II y Juana Enríquez. Así, sabemos que Guerau de Espés, mayordomo, había sido ordenado comisario y procurador de Fernando II en Sicilia y gobernador general de todas sus tierras en $1468^{34}$, mientras que Luis de Santángel, tesorero, era hijo del consejero y procurador fiscal de Juan II, también llamado Luis de Santánge ${ }^{35}$. Por su parte García de Heredia, ujier de armas de la infanta, había desempeñado ese mismo oficio previamente en la Casa de Juana Enríquez ${ }^{36}$, y posteriormente experimentaría una cierta proyección social y movilidad dentro de la Corte, habiendo sido identificado junto con dos familiares suyos, Jorge y Gonzalo de Heredia ${ }^{37}$, ejerciendo el cargo de contino $^{38}$ de Juan II en 1478 .

\footnotetext{
33 "Máxima autoridad femenina en la casa de la reina" encargada de organizar "todo lo relativo a la vida cotidiana en torno a la soberana", Narbona 2009, p. 103. A propósito de esta figura, que no aparece mencionada en las Ordinaciones de Pedro IV, pero sobre la que recaía buena parte de la gestión doméstica de la Casa, véase Narbona 2013, p. 155.

${ }^{34}$ AHPNZ, 4086, f. 4r-v.

${ }^{35}$ ACA, C, reg. 3365, ff. $167 \mathrm{v}-168 \mathrm{v}$.

${ }^{36}$ Gamero 2016, p. 114.

${ }^{37}$ Ibidem, p. 128.

${ }^{38}$ Cargo oficial sin "otra ocupación específica que la de cumplir los designios regios y vivir en la corte durante el tiempo en que fueran pagados como continos", quedando sujeto a las necesidades específicas de la persona titular de la Casa. Pelaz 2017, p. 126.
} 
Esto nos lleva a considerar otras prácticas frecuentes dentro de estas dinámicas de promoción social: en primer lugar, la especialización de ciertos individuos en un determinado ámbito dentro del cual fueron escalando puestos por su buen hacer o por la existencia de procesos de aprendizaje de un determinado oficio, lo que garantizaba un cierto ascenso profesional. Este es el caso de Juan de Peralta, escolar de la capilla de la infanta que, a finales del reinado de Juan II, aparece ejerciendo de capellán y lugarteniente del tesorero en la Casa del Rey ${ }^{39}$, pero también el de otros oficiales como Martín de Caparroso y Pedro de la Ferrán, mozos de espuelas al servicio de la infanta Juana y posteriormente monteros en Casa de Juan $\mathrm{II}^{40}$. En segundo lugar, esta especialización favoreció la movilidad de individuos que desempeñaron un mismo oficio simultánea o sucesivamente en varias instituciones cortesanas dependiendo de las necesidades de sus titulares. En este caso, Pedro de León aparece documentado como camarero de Juan II entre $1458^{41}$ y $1478^{42}$ y como contino de las damas y doncellas de la Casa de la Infanta por lo menos entre 1469 y 1472.

También hemos documentado la relación de parentesco de Diego y Pedro de León ${ }^{43}$, padre e hijo y ambos camareros en la Casa de Juan II, e identificado a otros individuos con su mismo apellido en las nóminas de oficiales reales de 1478: Carlos de León, camarero; Martín de León, ayudante de cámara; Dionis de León, paje; y Alonso, Gonzalo y Juan de León, continos ${ }^{44}$. Junto a ellos hemos detectado a un tal Juan de Ureña como ayudante de cámara del guardarropa entre 1469 y $1472^{45}$. El de ayudante de cámara era un cargo auxiliar al de camarero, puesto al que sus padres, Juan de Ureña e Isabel Rodríguez Muñoz, habían promocionado en $1461^{46}$, lo que nos lleva a pensar que situarse al servicio de reyes, reinas e infantes no sólo favorecía al oficial en cuestión mediante la adquisición de un mayor prestigio social, sino que le ofrecía herramientas de promoción tanto para sí mismo como para sus allegados, que dispondrían de fácil acceso al entorno cortesano mediante el desempeño de un oficio en el mismo ámbito en que sus familiares se habían especializado ${ }^{47}$.

${ }^{39}$ Ibidem, pp. 128-129.

${ }^{40}$ Ibidem, p. 131.

${ }^{41}$ ACA, C, reg. 3364, f. 179v; y ACA, C, reg. 3367, f. 6v.

${ }^{42}$ Gamero 2016, p. 128.

${ }^{43}$ AHPNZ, 4086, f. 1v.

${ }^{44}$ Gamero 2016, pp. 127-130.

${ }^{45}$ ACA, RP, MR, 619, ff. 34v y 62v.

${ }^{46}$ ACA, C, reg. 3359, ff. 114v-115r.

${ }^{47}$ A este propósito resultan interesantes las consideraciones realizadas en Dedieu, Windler 1998, pp. 201-223 sobre la entidad de las redes familiares como uno de los principales elementos en torno a los que se estructuraban, durante el antiguo régimen, las relaciones de poder. 


\section{EL ENTORNO FEMENINO DE LA INFANTA JUANA DE ARAGÓN}

El libro de cuentas de la infanta Juana de Aragón resulta especialmente útil para documentar algunas de las actividades y marcos de agencia femeninos en el espacio público a finales de la Edad Media. Entre las páginas redactadas por Luis de Santángel discurren mujeres de diverso origen y condición social que interactuaron con la infanta entre 1469 y 1472. Algunas de ellas, de muy bajo estatus jurídico, se situaron al servicio de Juana de Aragón dentro de su propia Casa, donde desempeñaron sin ningún tipo de remuneración tareas domésticas, de entretenimiento y exhibición de la dignidad de su titular y el boato que la acompañaba. Dentro de este grupo hemos identificado con nombre propio a Ana, esclava mencionada secundariamente en un pago realizado a Vicente de Alagón, dido o cuidador de $\mathrm{Mi}$ quelet, fill de Anna, sclava de casa de la dita senyora ${ }^{48}$ y a Bárbara, enana a quien la infanta mandó entregar 100 sueldos barceloneses con los que costear su vestimenta ${ }^{49}$.

En el mencionado libro de tesorería se recogen también una serie de pagos referidos a varias mujeres de la ciudad de Zaragoza que desempeñaron de forma autónoma actividades relacionadas con la artesanía y el comercio. Todas ellas se dedicaron a dos de los sectores más feminizados dentro del mundo laboral bajomedieval: la compraventa al detalle y la elaboración y venta de productos textiles y alimenticios ${ }^{50}$. De esta manera, en 1470 Ana Alegría, judía dedicada a la venta de lana y otros tipos de tela, recibió de la infanta 138 sueldos jaqueses y 9 dineros por la compra de ropa de cama y cierta cantidad de lana que posteriormente serviría para elaborar seis colchones per un lit que la dita senyora mana fer per al senyor rey ${ }^{51}$. Otro ejemplo en este ámbito es ofrecido por una vecina de la ciudad de oficio drapera, de quien no se especifica el nombre pero sí su estado civil -es mencionada como la viuda de Cabanyes- y los 135 sueldos que la infanta le entregó a cambio de varias telas con las que se elaboraron trajes para madona Tomasa y la mujer de Sancho Corneda, pastelera ${ }^{52}$. Estas dos últimas fueron las únicas mujeres, junto con una costurera musulmana llamada Fátima ${ }^{53}$, que desempeñaron un cargo oficial en la Casa de la infanta Juana, nuevamente en el marco de dos de

\footnotetext{
${ }^{48}$ ACA, RP, MR, 619, f. 56r.

${ }^{49}$ Ibidem, f. $50 \mathrm{v}$.

${ }^{50}$ A este propósito, resulta interesante la consulta de García 1990, pp. 7-82.

${ }^{51}$ ACA, RP, MR, 619, ff. 51v-52r.

${ }^{52}$ Ibidem, f. 50v.

${ }^{53}$ Ibidem, f. $52 \mathrm{v}$.
} 
los sectores artesanales mayoritarios entre las mujeres trabajadoras: la alimentación y el textil ${ }^{54}$.

Por otra parte, el grueso del entorno femenino de Juana de Aragón estaba compuesto por un número estable de mujeres de ascendencia nobiliaria que constituían su círculo más próximo, quedando perfectamente integradas en la cámara y el séquito de la infanta. Gracias a la especificidad de la Casa de las reinas, princesas e infantas, que constituía un espacio de mujeres institucionalizado (...) física y simbólicamente acotado ${ }^{55}$, aquellas que se situaban al servicio de la infanta o soberana disponían de un acceso directo tanto a la misma como a otros espacios de poder, contaban con la posibilidad de ejercer una profesión remunerada y, en el caso de haber ingresado en esta institución de muy jóvenes, recibían una esmerada educación. Además, todas estas mujeres quedaban introducidas en potentes redes relacionales, de afecto y solidaridad ${ }^{56}$ tanto entre sí mismas como con la titular y que, en muchos casos, se prolongaban una vez abandonada la $\mathrm{Casa}^{57}$. De este modo, la proximidad derivada de la convivencia diaria y las experiencias compartidas favorecía la creación de potentes vínculos entre estas mujeres, que llegaron a establecer con su titular relaciones articuladas en torno a

una amistad dialogante, fruto de la cercanía, la cotidianeidad y la palabra, como rasgos que favorecen el surgimiento de afectos e intereses que perseguir como una empresa común, en la que la vinculación relacional (...) jugará un papel decisivo en el devenir político, aunque a menudo de silencioso rastro ${ }^{58}$.

Precisamente por ello, la participación o injerencia en el proceso de composición de la Casa durante sus primeros años constituye un modo fundamental de controlar la capacidad de acción política de la infanta Juana y los

\footnotetext{
${ }^{54} \mathrm{Al}$ hilo de estas consideraciones, María del Carmen García Herrero indica cómo, en el Aragón bajomedieval, la presencia femenina en algunos de estos ámbitos fue tan significativa que "verbos como panificar y vender se conjugaron frecuentemente en femenino". García 2009, p. 589.

${ }^{55}$ Muñoz 2000, p. 125.

${ }^{56}$ En este sentido, era frecuente la inclusión en el séquito de las reinas, princesas o infantas de mujeres nobles en situación de vulnerabilidad, generalmente viudas con hijos a su cargo o jóvenes a las que su familia no podía dotar convenientemente, a quienes se ofrecía alojamiento, ciertas cuantías económicas para su mantenimiento y la posibilidad de concertar ventajosos enlaces matrimoniales. García, Pérez 2010.

${ }^{57}$ Sabemos, por ejemplo, que la reina María de Castilla forjó un estrecho vínculo con muchas de las mujeres que integraban o habían integrado su séquito, con quienes seguía manteniendo una fluida correspondencia en la que se preocupaba por su situación, llegando a intervenir en casos de enfermedad, fallecimiento y maltrato marital. Narbona 2009, pp. 107-109. Sobre los casos de maltrato marital en que intervinieron ésta y otras reinas, véase García 2014.

${ }^{58}$ Pelaz 2014, p. 296.
} 
puntos de apoyo e influencia sobre la misma en beneficio propio o del linaje al que se adscribían aquellas personas que participaban de la selección del personal de la infanta. Ya hemos avanzado que tanto Juan II como Juana Enríquez ejercieron un papel activo en la articulación de una embrionaria Casa de la Infanta que, algunos años más tarde, Juana de Aragón iría modelando y madurando como consecuencia de la edad, su recién adquirida experiencia política y la ampliación de sus espacios y círculos relacionales. De esta manera, quienes acompañaron a la infanta en el tránsito de la infancia a la adolescencia procedían mayoritariamente de la Corte y el entorno de las dignidades real y reginal. Ya aludimos con anterioridad al nombramiento de Juan de Ureña e Isabel Rodríguez Muñoz como camareros por parte de Juan II, así como a la designación de algunos de los servidores de la infanta por Juana Enríquez en su testamento. Entre estos últimos sobresale, indudablemente, Isabel de Mur $^{59}$, nombrada ama de la infanta y encargada de una tarea tan compleja como la de hacerse cargo de su cuidado y educación en un momento en el que su madre ya no iba a estar presente para supervisar ambas esferas. Sin embargo, en 1469, tan sólo un año después de su nombramiento por Juana Enríquez, quien aparece desempeñando este cargo es Isabel Muñoz ${ }^{60}$, que desaparece de la documentación en 1470. Ese año parece ocupar el puesto junto a Inés de Moya $^{61}$, quien tampoco vuelve a ser mencionada en años posteriores, lo que nos lleva a pensar que Juana de Aragón, que en ese momento ya había cumplido los 15 años, habría prescindido definitivamente del puesto de ama, más propio del entorno de una niña que del de una joven casadera.

\begin{tabular}{|l|l|c|c|c|}
\hline CARGO & NOMBRE & $\begin{array}{c}\text { QUITACIÓN } \\
\text { ORDINARIA }\end{array}$ & $\begin{array}{c}\text { AYUDAS DE } \\
\text { COSTA (1469) }\end{array}$ & $\begin{array}{c}\text { AYUDA VESTIDOS } \\
(1470)\end{array}$ \\
\hline \multirow{2}{*}{ Ama } & Isabel Muñoz & 90 & 40 & - \\
\cline { 2 - 5 } & Inés de Moya & - & - & 200 \\
\hline \multirow{4}{*}{ Damas } & Isabel de Urrea & 900 & 400 & - \\
\cline { 2 - 5 } & Leonor de Navarra & 120 & 90 & - \\
\cline { 2 - 5 } & Ana de Navarra & 120 & 90 & 460 \\
\cline { 2 - 5 } & Aldonza Enríquez & 120 & 90 & 460 \\
\hline
\end{tabular}

${ }^{59}$ Genovés 1943, p. 7. Isabel de Mur era la esposa de Pedro Ximénez de Urrea, segundogénito del virrey de Sicilia Lope Ximénez de Urrea. Galé 2013, p. 72.

${ }^{60}$ ACA, RP, MR, 619, ff. 29r, 35r y 42r. Dada la coincidencia de apellidos y la naturaleza del cargo desempeñado, que implica una notable responsabilidad, amplios conocimientos sobre el funcionamiento de la Casa y la existencia de una cierta relación de confianza entre la infanta y su ama, cabe preguntarse si la identidad de Isabel Muñoz podría coincidir con la de Isabel Rodríguez Muñoz, nombrada camarera de Juana de Aragón en 1461 por Juan II, pudiendo haber pasado a desempeñar el cargo de ama de la infanta ocho años después, en 1469.

${ }^{61}$ ACA, RP, MR, 619, f. 50v. También se documenta en ACA, C, reg. 3419, f. 160r-v. 


\begin{tabular}{|l|l|c|c|c|}
\hline CARGO & NOMBRE & $\begin{array}{c}\text { QUITACIÓN } \\
\text { ORDINARIA }\end{array}$ & $\begin{array}{c}\text { AYUDAS DE } \\
\text { COSTA (1469) }\end{array}$ & $\begin{array}{c}\text { AYUDA VESTIDOS } \\
(1470)\end{array}$ \\
\hline \multirow{4}{*}{ Doncellas } & Leonor de Híjar & 90 & 40 & - \\
\cline { 2 - 5 } & Damiata de Alagón & 120 & 40 & 200 \\
\cline { 2 - 5 } & Sibila de Alagón & 120 & 40 & 200 \\
\cline { 2 - 5 } & María de Urriés & 90 & 40 & 200 \\
\cline { 2 - 5 } & Violante de Jarro & 90 & 40 & - \\
\cline { 2 - 5 } & Mari Bernat & 90 & 40 & 200 \\
\cline { 2 - 5 } & Violante de Ódena & 90 & 40 & 200 \\
\cline { 2 - 5 } & Orfresina de Vilaragut & 120 & 40 & 208 \\
\cline { 2 - 5 } & Blanca de Rocabertí & - & - & 200 \\
\hline
\end{tabular}

Fig. 3. Quitaciones ordinarias complementos de las amas, damas y doncellas de la Casa de Juana de Aragón en 1469 y 1470 (en sueldos barceloneses).

La influencia materna en la composición de la Casa de Juana de Aragón queda demostrada, también, con la inclusión en ella de Aldonza Enríquez (14501520), hija de Fadrique Enríquez -Almirante Mayor de Castilla- y Teresa de Quiñones y, por tanto, hermana de Juana Enríquez por parte de padre. En cierta manera, Aldonza Enríquez representaba los intereses castellanos en la Corona de Aragón o, al menos, los vínculos que el matrimonio regio había mantenido con la corona vecina, si bien la posesión de los señoríos de Elche y Crevillente y su inclusión en el linaje de los Cardona tras su matrimonio con Juan Ramón Folch, I duque de Cardona, en $1467^{62}$, demuestran que Aldonza Enríquez estaba perfectamente integrada en la Corte aragonesa. Sea como fuere, tanto su integración en el séquito de su sobrina como su enlace con el duque de Cardona constituyen una muestra evidente del proceso de transformación de la nobleza aragonesa iniciado a comienzos del siglo XV, a raíz de la coronación de Fernando I. La subida al trono de los Trastámara favoreció la llegada a la Corona de Aragón de individuos pertenecientes a algunos de los linajes castellanos más preeminentes, que pronto entroncaron con reputadas familias aragonesas y llegaron a ocupar posiciones de una considerable entidad en el seno de la corona ${ }^{63}$.

${ }^{62}$ Documentado en www.geni.com [consulta: 09/05/2018].

${ }^{63}$ Esta práctica se intensificó durante el reinado de Juan II de Aragón (1458-1479), quien situó en su entorno más cercanos a muchos de los individuos que habían permanecido a su lado desde que fuese infante de Castilla. Buena parte de ellos obtuvieron un puesto oficial en la Casa de Juan II, mayoritariamente en su espacio más íntimo y, por tanto, de mayor cercanía al soberano: la cámara. En consecuencia, y como recompensa por sus muchos años de servicio al rey, muchos de estos oficiales castellanos recibieron, además, interesantes rentas y propiedades en la Corona de Aragón y entroncaron con algunos de los linajes nobiliarios más destacados o con miembros de las familias más destacadas entre las élites municipales de las principales localidades de la corona. En este sentido, el caso más paradigmático lo constituye el linaje de los Rebolledo, analizado en Velasco 2019, pp. 202-203 y 210. 
Por otra parte, a excepción de Isabel Muñoz e Inés de Moya, las mujeres nobles que confluyeron en el entorno de la infanta Juana eran damas o doncellas, división que llevaba aparejado tanto un matiz de edad y estatus jurídico, que señalaba la distinción entre solteras y casadas, como un matiz de oficio, dado que las doncellas desempeñaban ciertas tareas domésticas y de acompañamiento de las que las damas o dueñas eran eximidas ${ }^{64}$. En el caso de las doncellas de Juana de Aragón, parece haber existido una clara intencionalidad por parte de sus progenitores de integrar en su séquito a jóvenes procedentes de todos los territorios de la Corona de Aragón para satisfacer a los principales linajes nobiliarios, garantizar la estabilidad del reinado y la posición de la propia infanta y propiciar el establecimiento de una amplia red de contactos entre Juana de Aragón y los distintos territorios de la corona que le permitirían desarrollar un criterio propio mediante el que constituir, de forma autónoma, su séquito en años posteriores. Todo ello justifica la confluencia, en un primer momento, de jóvenes de la nobleza valenciana y catalana como Orfresina de Vilaragut y Blanca de Rocabertí65 , junto con otras de los principales linajes aragoneses como Leonor de Híjar ${ }^{66}$ y Sibila y Damiata de Alagón ${ }^{67}$.

Junto a amas y doncellas, también las damas o dueñas formaban parte del círculo de confianza de Juana de Aragón. Dentro de esta categoría mencionamos con anterioridad a Isabel de Urrea, de quien nos llamaron la atención sus elevadas quitaciones ordinarias y ayudas de costa, hecho que habíamos atribuido a un posible papel preponderante dentro de la cámara de la infanta en tanto que cambrera mayor. No obstante, tampoco sería extraño que Isabel de Urrea contase con un séquito propio y dedicase parte de su salario al mantenimiento de este ${ }^{68}$. Junto a ello, cobra especial fuerza la hipótesis de la

\footnotetext{
${ }^{64}$ Narbona 2009, pp. 102-105.

${ }^{65}$ No hemos podido identificar la ascendencia de esta doncella, perteneciente a uno de los linajes catalanes más significados a favor de Juan II durante la guerra civil catalana (1462-1472). Por ello, es posible que su inclusión en la Casa de la Infanta en 1470 hubiese sido un modo de recompensar la lealtad de su familia. Sobre el linaje de los Rocabertí y su participación en la guerra civil catalana véase Sobrequés, Sobrequés 1973.

${ }^{66}$ Aunque no hayamos podido documentar su filiación, es posible que fuese hija o familiar de Juan Fernández de Híjar y Cabrera, duque de Híjar y Aliaga y conde de Castellote, que ejerció los cargos de mayordomo mayor de Alfonso V y Fernando II y camarlengo del príncipe Carlos de Viana. Casaus 2007; Moreno 2018. Sobre la promoción social del linaje de los Híjar en la Corona de Aragón y, especialmente, sobre la figura de Juan Fernández de Híjar, véase Laliena, Iranzo 2016.

${ }^{67}$ Hermanas, hijas de Artal de Alagón y Juana Fernández de Híjar. Documentadas en Pedro Garcés de Cariñena, Nobiliario de Aragón, ed. Ubieto Arteta, p. 309.

${ }^{68}$ Esta práctica era relativamente frecuente entre las mujeres más destacadas dentro del entorno de reinas o infantas. En este sentido, no debemos olvidar que Isabel de Urrea pertenecía a uno de los linajes más reputados del reino de Aragón, que en 1488 llegó a recibir de Fernando II el condado de Aranda. Navarro 2009. Sobre el linaje de los Urrea, véase Galé 2013. Lamentablemente, no hemos podido documentar la ascendencia de Isabel de Urrea, un aspecto que
} 
existencia de un estrecho vínculo entre Juana e Isabel de Urrea que se habría prolongado durante largo tiempo, tal y como parece atestiguar el salvoconducto que Juan II emitió en agosto de 1477 para garantizar su seguridad personal y la protección de sus tierras y bienes ante un inminente viaje ${ }^{69}$. Pero esta fecha coincide con otro viaje: el de la infanta Juana a Nápoles para contraer matrimonio con Ferrante I, lo que parece verificar la continuidad de Isabel de Urrea al servicio de Juana de Aragón una vez coronada como Juana III.

Por último, resulta significativo que el resto de damas procediesen de la propia familia de la infanta ${ }^{70}$. Así, Ana de Navarra (1451-1477) y Leonor I de Navarra (1426-1479) formaron parte, junto a Aldonza Enríquez, del séquito de Juana de Aragón. Indudablemente, la presencia de estas mujeres en el entorno más próximo a la infanta suponía una vía de prestigio y reconocimiento mutuo, pero también un relevante mecanismo de acción política del que Juan II se habría servido para garantizar la estabilidad de la Corona de Aragón en un momento en que buena parte de sus territorios patrimoniales se veían amenazados por las luchas intestinas en Navarra y Cataluña y por la injerencia castellana en las mismas. En este sentido, la presencia de Leonor y Ana de Navarra en la Casa de Juana de Aragón no resulta una cuestión baladí sino, más bien, una inteligente estrategia política para asegurar su fidelidad a la infanta y, por extensión, a los intereses de su linaje en el momento de mayor confrontación entre Juan II y Leonor de Navarra. Esta era la hija de Juan II y Blanca de Navarra y heredera a dicho reino una vez que sus hermanos mayores, Blanca y Carlos de Viana, fueron desheredados. Aunque en un primer momento Leonor de Navarra, condesa de Foix por su matrimonio con Gastón IV y lugarteniente general de Navarra desde 1455, había apoyado los intereses de su padre durante la guerra civil que enfrentó a beamonteses y agramonteses $^{71}$, sus desavenencias aumentaron considerablemente tras la guerra. De hecho, Leonor llegó a ser destituida por su padre en 1469 aunque continuó ejerciendo la lugartenencia como si no se hubiera producido el relevo ${ }^{72}$,

hubiera resultado particularmente interesante para comprender mejor las características de su presencia y estatus en la Corte.

${ }^{69}$ ACA, C, reg. 3391, f. 51r. Con este documento, Juan II aseguraba que Isabel de Urrea pudiese circular libremente, sin ser arrestada ni detenida, mientras siguiese al servicio de su hija, y prohibía que se actuase contra las propiedades que dicha noble tenía en el Principado de Cataluña, y particularmente contra la villa de Albí y el lugar de Cervià, en la actual comarca de Les Garrigues.

${ }^{70}$ De nuevo, remitimos al árbol genealógico de la infanta Juana presente al final de este artículo.

${ }^{71}$ Véase Ramírez 1990.

${ }^{72}$ Ramírez 2014, p. 725. Leonor de Navarra llegó a reinar muy brevemente tras la muerte de Juan II, entre el 28 de enero de 1479 y el 12 de febrero de dicho año, fecha de su propia defunción. Ramírez 1999. 
lo que, sin duda, aumentó la crispación ${ }^{73}$. En este contexto, la presencia de Leonor en el entorno de Juana de Aragón debe ser entendida como una forma de control por Juan II, dado que la concesión de ciertas retribuciones por los servicios prestados a la infanta llevaba implícito un matiz de sumisión y lealtad a la titular de la Casa.

Por su parte, Ana de Navarra era la hija de Carlos de Viana y María de Armendáriz y, por tanto, sobrina de la infanta ${ }^{74}$. En 1461, y tras la muerte de su padre, Ana ingresó en la Casa de Juana de Aragón con sólo 10 años, y permaneció en ella hasta que una década más tarde fue casada con el castellano Luis de la Cerda, duque de Medinaceli ${ }^{75}$ y destacado defensor de las aspiraciones al trono castellano de la que pronto se convertiría en Isabel I. Tanto su inclusión en la Casa de su tía casi a modo de rehén como su enlace con Luis de la Cerda, llevado a cabo por intermediación de Juan II y el futuro Fernando II, obedecían a una clara estrategia real para evitar cualquier posible reivindicación de sus derechos al trono de Navarra. Sin embargo, esta estrategia pareció fallar cuando Ana de Navarra y su esposo reclamaron los derechos sucesorios que Carlos de Viana había tratado de conferir a su hija en su último testamento, si bien ambos cónyuges terminarían renunciando a cualquier aspiración sobre el trono navarro como consecuencia de la significación de Fernando II en favor de los derechos de su hermanastra, Leonor de Navarra. Además, en 1477, una vez fallecida Ana de Navarra, Luis de la Cerda contrajo un acuerdo con la ya reina Isabel I y Fernando, rey consorte de Castilla, por el cual recibió importantes contraprestaciones económicas a cambio de su lealtad a los intereses regios y de aceptar el compromiso de servir a la reina durante las campañas de Andalucía, lo que le alejaría definitivamente de Navarra y diluiría, por tanto, sus aspiraciones al trono ${ }^{76}$.

\section{CONCLUSIONES}

La figura de Juana de Aragón ofrece la imagen de una vida marcada, ya desde el tiempo que pasó como rehén del arzobispo de Toledo en 1463, por los intereses y estrategias de la rama aragonesa de los Trastámara. No obstante, este emplazamiento al servicio de su propio linaje no resulta sinónimo de pasividad ni, mucho menos, de desinterés o alejamiento de las esferas

\footnotetext{
${ }^{73}$ Los enfrentamientos entre Leonor de Navarra y Gastón IV de Foix, por una parte, y Juan II y Fernando II, por otra, pueden observarse en: Coll 1952; Suárez 1982; Ramírez 1999, 2014.

${ }^{74}$ Gran Enciclopedia Aragonesa (GEA), voz “Ana de Aragón y de Navarra”, en http://www. enciclopedia-aragonesa.com [consulta: 02/05/2018].

${ }^{75}$ Núñez 2008, p. 11.

${ }^{76}$ Sánchez 2001, pp. 68-70.
} 
de gobierno. Al contrario, las más de tres décadas en las que ejerció como lugarteniente general de Cataluña y de Nápoles suponen claros indicativos de la importancia que revistió la acción política de Juana de Aragón. En este sentido, reconstruir y analizar su entorno social en el momento previo a su entrada de lleno en la esfera política aragonesa se revela necesario para comprender cuáles fueron las bases relacionales y las vías o estrategias que le permitieron ampliar su campo de agencia en el ámbito público y los espacios de gobierno más destacados de la Corona de Aragón algunos años más tarde.

Partiendo de este punto, los datos ofrecidos por Luis de Santángel en el libro de tesorería de Juana de Aragón correspondiente a los años 1469-1472 han permitido una reconstrucción lo más fidedigna posible del entorno social de la infanta y el extenso entramado de oficiales y otras personas situadas a su servicio. La identificación con nombre y apellido de estos individuos, así como la información relativa a sus salarios, cargos y competencias, han facilitado, por una parte, el trazado de la estructura jerárquica existente en el seno de la institución analizada y, por otra, el reconocimiento de aquellas redes de amistad, alianza y solidaridad que conectaban a la infanta con sus servidores y a todos ellos con otros espacios de poder. Esto ha puesto en evidencia, a su vez, la constante fluctuación de privilegios y beneficios entre Juana de Aragón y quienes integraban su Casa, beneficiados con retribuciones económicas más o menos elevadas en función del cargo ejercido y de su grado de cercanía a la titular. Junto a los beneficios pecuniarios, este ámbito ha demostrado constituir una importante plataforma para la adquisición de prestigio y el ascenso social gracias al trazado de alianzas matrimoniales y la promoción personal o de algún familiar a otros cargos e instituciones.

En otro orden de cosas, el análisis particular de esta fuente permite documentar una parte destacada del trabajo extradoméstico de las mujeres en las ciudades bajomedievales, así como el trabajo femenino oficial y remunerado al servicio de Juana de Aragón y el de otras mujeres que, sin recibir en contrapartida ningún tipo de retribución económica, desempeñaron tareas domésticas y de acompañamiento dentro de la Casa de la Infanta. Asimismo, pone de relieve la importancia de la Casa como un espacio femenino institucionalizado. En este sentido, las amas, damas y doncellas que sirvieron a Juana de Aragón gozaron de ciertos privilegios como el acceso a una cuidada educación, el recurso a los ya mencionados mecanismos de promoción social y el disfrute de una considerable autonomía económica. Sin embargo, paralelamente se convirtieron en piezas clave mediante las cuales controlar la capacidad de acción política de la infanta y sus principales puntos de apoyo e influencia, tal y como evidencian las distintas estrategias llevadas a cabo por Juan II a la hora de introducir a determinadas mujeres de su familia en los círculos sociales y afectivos más próximos a su hija. 
Este es, sin lugar a dudas, el caso de Leonor de Navarra, hermanastra de Juana de Aragón, y el de su sobrina Ana de Navarra. Tal y como hemos intentado señalar en páginas anteriores, la presencia de ambas mujeres entre las damas y doncellas que componían el séquito de Juana de Aragón no fue fruto del azar. Al contrario, tanto la integración de Ana y Leonor de Navarra en la Casa de la Infanta como la recepción regular de una cantidad económica en concepto de quitación ordinaria obedecen a una estrategia meditada y ejecutada por Juan II para asegurar la estabilidad de la Corona de Aragón y mantener el reino de Navarra entre sus dominios patrimoniales. Para ello, intentó asegurar la lealtad de Leonor de Navarra a su medio hermana e incrementar su control sobre la misma al tiempo que mantenía en la Corte a su nieta, hija de Carlos de Viana, durante más de una década, como una suerte de rehén.

Por último, los años en los que se enmarca el libro de cuentas analizado en este artículo corresponden con el fin de la niñez de Juana de Aragón y su entrada en la esfera pública aragonesa. Las noticias relativas al nombramiento de oficiales y otro tipo de servidores privativos de la infanta revelan la participación activa de Juan II y Juana Enríquez en la selección y designación de aquellas personas que constituirían los círculos más cercanos a su hija. Ambos progenitores intervinieron, en mayor o menor medida, en la gestación de esta embrionaria Casa de la Infanta, que iría modificándose y consolidándose con el paso de los años como fruto de la progresiva madurez de su titular, la ampliación de sus redes de sociabilidad y las dinámicas políticas, sociales y económicas de la Corona de Aragón. Unas dinámicas que propiciaron el emplazamiento de determinadas personas al servicio de Juana de Aragón como una vía más o menos eficaz de garantizar la paz y estabilidad del conjunto de territorios de la corona y salvaguardar los intereses de la infanta y sus familiares más cercanos, Juan II y Fernando II. Finalmente, esta primera Casa de la Infanta contribuyó a consolidar la situación de su titular en la esfera pública, proporcionándole la ayuda necesaria para ocupar puestos de gobierno que, como la lugartenencia general de Cataluña, implicaban una marcada autoridad y la posesión de potentes redes clientelares y abundantes apoyos que garantizasen la obediencia de sus súbditos. Asimismo, el funcionamiento de este espacio doméstico y de poder durante el periodo aquí analizado favoreció la adquisición de una cierta experiencia por parte de su titular, que, posteriormente, se vería ampliada a raíz de su ascenso al trono de Nápoles. Aunque se haya documentado la continuidad de ciertos oficiales y miembros de su séquito en el entorno de la infanta Juana desde su primera adolescencia hasta su coronación como reina de Nápoles -e incluso más allá de dicho acontecimiento-, queda pendiente comparar la composición de la Casa primitiva de Juana de Aragón con la Casa de la Infanta durante su etapa como lugarteniente general de Cataluña, si bien las referencias halladas hasta el momento a propósito de los años 1475-1477 son muy escasas y fragmentarias. 


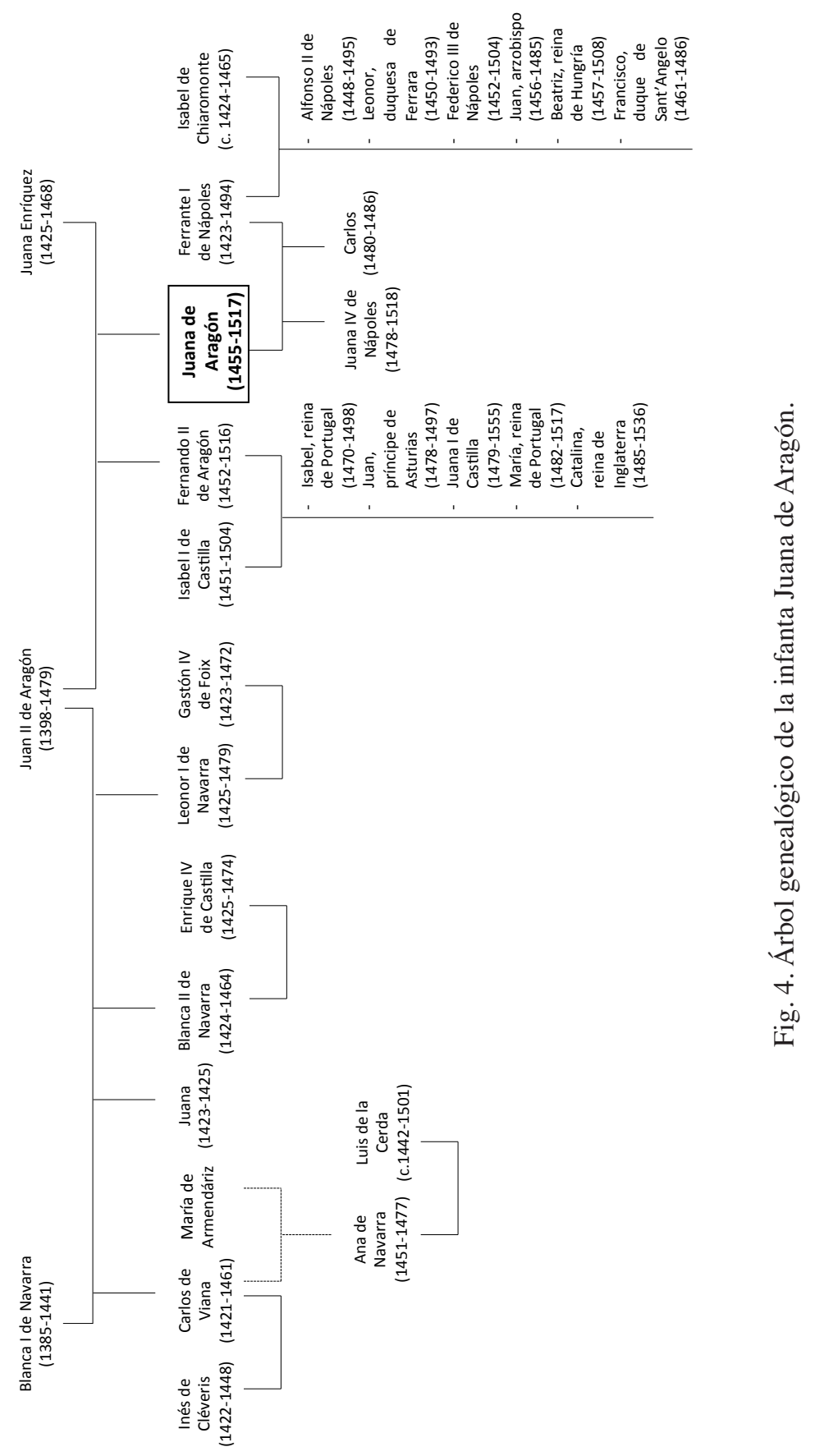




\section{BIBLIOGRAFÍA CITADA}

FUENTES PRIMARIAS

Pedro Garcés de Cariñena, Nobiliario de Aragón anotado por Zurita, Blancas y otros autores, ed. María Isabel Ubieto Arteta, Zaragoza, Anúbar, 1983.

Pedro IV de Aragón, Ordinacions de la Casa i Cort de Pere el Cerimoniós, ed. Francisco M. Gimeno, Daniel Gonzalbo y Josep Trenchs, Valencia, Universitat de València - Acadèmia Valenciana de la Llengua, 2009.

Vázquez, Dechado de amor hecho por Vazquez a peticion del Cardenal de Valencia, endereçado a la Reyna de Napoles, en Vigier, Françoise (ed.), Cuestión de amor (Valence, Diego de Gumiel, 1453), París, Publications de la Sorbonne, 2006, pp. 372-390.

\section{REFERENCIAS BIBLIOGRÁFICAS}

Beauchamp, Alexandra (2013), Les Ordinacions de la Casa i Cort de Pierre IV d'Aragon et le nombre des serviteurs royaux, en Beauchamp, Alexandra (coord.), Les entourages princiers à la fin $\mathrm{du} \mathrm{Mo-}$ yen Âge: une approche quantitative, Madrid, Casa de Vélazquez, pp. 43-56.

Casaus Ballester, María José (2007), El señorío, luego ducado de Hijar, trayectoria familiar y acumulación de títulos nobiliarios, en Casaus Ballester, María José (coord.), Jornadas sobre el Señorío-Ducado de Hijar: siete siglos de historia nobiliaria, Híjar, Centro de Estudios del Bajo Martín, pp. 159-186

Coll Julià, Núria (1952), El dilema franco-español en la política de Doña Leonor de Navarra, "Príncipe de Viana" 48-49, pp. 413-418.

Croce, Benedeto (1894), La corte delle tristi regine a Napoli, "Archivio storico per le provincie napoletane" 19, pp. 354-375.

Dedieu, Jean Pierre; Windler, Christian (1998), La familia, ¿una clave para entender la historia política? El ejemplo de la España moderna, "Studia Histórica: Historia Moderna" 18, pp. 201-223.

Earenfight, Theresa (2005), Preface: Partners in politics, en Earenfight, Theresa (ed.), Queenship and Political Power in Medieval and Early Modern Spain, Burlington, Ashgate, pp. XIII-XXVIII.

Earenfight, Theresa (2018), A Precarious Household: Catherine of Aragon in England, 1501-1504, en Earenfight, Theresa (ed.), Royal and Elite Households in Medieval and Early Modern Europe: More than just a Castle, Leiden, Boston, Brill, pp. 338-356. 
Echevarría Arsuaga, Ana (2002), Catalina de Lancaster: reina regente de Castilla (1372-1418), Hondarribia (Guipúzcoa), Nerea.

Falcón Pérez, María Isabel (2006), El municipio de Zaragoza entre 1468 y 1472 según los libros de actos comunes de sus jurados, Zaragoza, Ayuntamiento de Zaragoza.

Fernández Murga, Félix (1959), Dona Juana de Aragon reina de Napoles, en Studi in onore di Riccardo Filangieri, Nápoles, L'Arte tipografica, vol. 2, pp. 175-196.

Gaglione, Mario ( $\sin$ año), I luoghi del potere della triste reyna Giovanna III infanta della real casa d'Aragona, regina di Sicilia e Gerusaleme, recurso online consultado en www.academia.edu [consulta: 15/03/2018].

Galé Casajús, Enrique (2013), Biografía del virrey de Sicilia Lope Ximénez de Urrea, en Criado Mainar, Jesús (coord.), El sepulcro de Lope Ximénez de Urrea, vizconde de Urrea y virrey de Sicilia, Zaragoza, Institución Fernando el Católico, pp. 11-100.

Gamero Igea, Germán (2016), Epílogo de un reinado y desmembramiento de una Corte: servidores de Juan II de Aragón a su muerte, "Medievalismo" 21, pp. 109-133.

García Herrero, María del Carmen (1990), Las mujeres en Zaragoza en el siglo $X V$, Zaragoza, Ayuntamiento de Zaragoza.

García Herrero, María del Carmen (2009), La contribución de las mujeres a la economía de las familias dedicadas a actividades no agrarias en la Baja Edad Media española, en Cavaciocchi, Simonetta (coord.), La famiglia nell'economia europea. Seccoli XIII-XVIII = The Economic Role of the Family in the European Economy from the $13^{\text {th }}$ to the $18^{\text {th }}$ Centuries. Atti della "Quarantesima settimana di studi", 6-10 aprile 2008, Firenze, Firenze University Press, pp. 569-598.

García Herrero, María del Carmen (2013), Un tiempo de añoranza y aprendizaje: María de Castilla y sus primeros años en la Corona de Aragón, "Storia delle donne" 9, pp. 97-116.

García Herrero, María del Carmen (2014), Solidaridad femenina ante el maltrato marital a finales de la Edad Media. Algunas intervenciones de la reina de Aragón, en García Herrero, María del Carmen; Pérez Galán, Cristina (coords.), Mujeres de la Edad Media: actividades políticas, socioeconómicas y culturales, Zaragoza, Institución Fernando el Católico, pp. 113-137.

García Herrero, María del Carmen (2017), Presentación del dossier monográfico: Reginalidad y fundaciones monásticas en la Baja Edad Media Peninsular, "Edad Media. Revista de Historia" 18, pp. 11-15.

García Herrero, María del Carmen; Pérez Galán, Cristina (2010), Colocar en matrimonio: el caso de Marquesa de Alagón y la intervención de 
la reina María (1448-1451), en Homenaje al profesor Eloy Benito Ruano, Murcia, Sociedad Española de Estudios Medievales - Universidad de Murcia, tomo I, pp. 307-318.

Genovés, Vicente [1943] La triste Reina de Nápoles, hermana del Rey Católico, Madrid, Ediciones Historia.

Gran Enciclopedia Aragonesa (GEA), voz "Ana de Aragón y de Navarra”, http://www.enciclopedia-aragonesa.com [consulta: 02/05/2018].

Laliena Corbera, Carlos; Iranzo Muñío, María Teresa (2016), Mercados de crédito, deuda censal y señoríos en la Corona de Aragón (siglo XV), en Laliena Corbera, Carlos; Lafuente Gómez, Mario (coords.), Consumo, comercio y transformaciones culturales en la Baja Edad Media: Aragón, siglos XIV-XV, Zaragoza, Grupo CEMA - Universidad de Zaragoza, pp. 233-273.

Moreno Meyerhoff, Pedro (2018), Historia genealógica de la Casa de Hijar: los descendientes del Rey Don Jaime I el Conquistador (siglos XIIIXXI), Barcelona, Difusión Publicaciones y Vídeos.

Muñoz Fernández, Ángela (2000), Relaciones femeninas y activación de los mecanismos del privilegio y la merced: la Casa de Isabel I de Castilla, en Segura Graíño, Cristina (coord.), Las mujeres y el poder: representaciones y prácticas de vida, Madrid, Asociación cultural Al-Mudayna, pp. 15-134.

Muñoz Fernández, Ángela (2002), La Casa delle Regine. Uno spazio político nella Castiglia del Quattrocento, "Genesis. Rivista della Società italiana delle storiche" I/2, pp. 71-95.

Narbona Cárceles, María (2009), Noblas donas. Las mujeres nobles en la Casa de María de Castilla, reina de Aragón (1416-1458), "STVDIVM. Revista de Humanidades" 15, pp. 89-113.

Narbona Cárceles, María (2013), “De Casa de la senyora reyna. L'entourage domestique de Marie de Castille, épouse d'Alphonse le Magnanime (1416-1458)", en Beauchamp, Alexandra (coord.), Les entourages princiers à la fin du Moyen Âge: une approche quantitative, Madrid, Casa de Vélazquez, pp. 151-167.

Navarro Espinach, Germán (2009), La formación de los señoríos del condado de Aranda, en Casaus Ballester, María José (coord.), El Condado de Aranda y la nobleza española en el Antiguo Régimen, Zaragoza, Institución Fernando el Católico, pp. 65-84.

Núñez Bespalova, Marina (2008), Origen del linaje de la Cerda y de las casas y mayorazgos que de ella proceden: BNE: MS 3454, "Revista de literatura medieval" 20, pp. 7-27.

Pelaz Flores, Diana (2013), "Queenship: teoría y práctica del ejercicio del poder en la Baja Edad Media castellana", en Jiménez Alcázar, Juan 
Francisco y Val Valdivieso, María Isabel del (coords.), Las mujeres en la Edad Media, Monografías de la Sociedad Española de Estudios Medievales, 3, pp. 277-287.

Pelaz Flores, Diana (2014), Tejiendo redes, estrechando lazos. Amistad femenina, protección y promoción social en la Casa de la Reina en Castilla (1406-1454), en García-Fernández, Miguel; Cernadas Martínez, Silvia (eds.), Reginae Iberiae. El poder regio femenino en los reinos medievales peninsulares, Santiago de Compostela, Universidad de Santiago de Compostela, pp. 273-296.

Pelaz Flores, Diana (2017), La Casa de la Reina en la Corona de Castilla (1418-1496), Valladolid, Ediciones Universidad de Valladolid, 2017.

Pelaz Flores, Diana (2018), Reynante(s) en vno. Fundamentación teórica del poder de la pareja regia en la Corona de Castilla durante la Baja Edad Media, "Anuario de Estudios Medievales" 48/2, pp. 845-869.

Pelaz Flores, Diana y Val Valdivieso, María Isabel del (2015), "La historia de las mujeres en el siglo XXI a través del estudio de la reginalidad medieval", Revista de Historiografía, 22, pp. 101-127.

Ramírez Vaquero, Eloísa (1990), Solidaridades nobiliarias y conflictos políticos en Navarra, 1387-1464, Pamplona, Institución Príncipe de Viana.

Ramírez Vaquero, Eloísa (1999), La reina Blanca y Navarra, "Revista Príncipe de Viana" 217, pp. 323-340.

Ramírez Vaquero, Eloísa (2014), Leonor (31/1/1426-12/11/1479). Reina titular de Navarra, condesa de Foix, en Pavón, Julia (dir.), Reinas de Navarra, Madrid, Sílex, pp. 711-733.

Sánchez González, Antonio (2001), Don Luis de la Cerda, 500 años después, "Revista de Historia de El Puerto" 27, pp. 65-86.

Scandone, Adele (1929), Le tristi reyne di Napoli Giovanna III e Giovanna $I V$, "Archivio storico per le provincie napoletane" 14, pp. 114-155; 15, pp. 151-189.

Silleras Fernández, Nuria (2003), Queenship en la Corona de Aragón en la Baja Edad Media: estudio y propuesta terminológica, "La corónica: A Journal of Medieval Hispanic Languages, Literatures \& Cultures" 32/1, pp. 119-133.

Sobrequés i Vidal, Santiago; Sobrequés i Callicó, Jaume (1973), La guerra civil catalana del segle XV. Estudis sobre la crisi social i econòmica de la Baixa Edat Mitjana, Barcelona, Edicions 62.

Suárez Fernández, Luis (1982), Fernando el Católico y Leonor de Navarra, "En la España medieval" 3, pp. 619-638. 
Velasco Marta, Irene (2019), De la ciudad a la corte. Una aproximación a las relaciones entre la oligarquía municipal de Zaragoza y Juan II de Aragón (1458-1479), "Revista de Historia Jerónimo Zurita" 94, pp. 195-214.

Vicens Vives, Jaime (2003), Juan II de Aragón (1398-1479): monarquía y revolución en la España del siglo XV, Barcelona, Urgoiti editores.

Fecha de recepción del artículo: marzo 2019

Fecha de aceptación y versión final: diciembre 2019 